\title{
Mechanical device the Penumbra system in the management of acute stroke: Report of five cases
}

\author{
Vikram Huded, Rashmi Saraf, Uday Limaye \\ Division of Interventional Neuroradiology, Department of Radiology, KEM Hospital, Mumbai, India
}

\author{
Address for correspondence: Dr. \\ Uday Limaye, \\ Division of Interventional \\ Neuroradiology, Department \\ of Radiology, KEM Hospital, \\ Mumbai - 400 012, India. E-mail: \\ udaylimaye123@gmail.com
}

\begin{abstract}
Use of mechanical devices in acute ischemic stroke has shown promise not only in recanalization rates but also with better clinical outcome and also extension of the window period to 8 hours. This is the first reported series of use of mechanical devices in India. We report five patients with acute stroke in whom mechanical devices (Penumbra System, Alameda, California) were used for thrombolysis. All the treated vessels (100\%) were successfully re-canalized, Trials In Myocardial Infarction (TIMI) score of 3. At 90-day follow-up, of the 5 patients treated, 2 had modified Rankin score $(\mathrm{mRS})$ of $<2$. This small series shows the safety and efficacy of the Penumbra System in the thrombolysis of large vessel occlusive disease.
\end{abstract}

Key words: Acute stroke, mechanical thrombolysis, re-canalization, penumbra system

\section{Introduction}

Mortality in large vessel, basilar artery, internal carotid artery " $\mathrm{T}$ " and middle cerebral artery-M1 segment, occlusive strokes is particularly high despite the best available medical therapy. Trials of mechanical devices in large vessel occlusive stroke have shown higher rates of re-canalization. ${ }^{[1-3]}$ Penumbra System (Alameda, California) ${ }^{[3]}$ is the first mechanical thrombectomy device approved by Drug Control General of India for use in acute ischemic stroke.

We report five patients with acute stroke in whom mechanical devices were used for thrombolysis. This is the first reported series of use of mechanical devices in India.

\section{Case Report}

\section{Summary of five cases}

Five patients with acute stroke were treated with Penumbra System, over a period of 6 months at our center. The clinical features and follow up of all the five patients are summarized in Table 1 . The mean age was 38.8 years. At presentation, mean National Institute of Health Stroke Scale (NIHSS) score was 26.8. Two patients had middle cerebral artery (MCA) occlusion and three had basilar artery (BA) thrombosis, The mean duration of illness was 5.8 hours (2 hours in MCA and 8.33 hours in BA). The mechanism of stroke was cardio embolic in four patients (Case 1, 3, 4, and 5) and in Case 2 the cause of the thrombosis could not be established.

Case 3 and 4 presented within 3 hours but both were ineligible for IV thrombolysis as they were on anticoagulant medication. In both of them computed tomography (CT) brain was normal, Even though case 5 presented beyond 8 hours we did mechanical thrombolysis as there were no significant $\mathrm{T} 2$ changes in MRI with significant Diffusion defects and occlusion of Basilar artery.

Penumbra System (Alameda, California) was used for mechanical thrombolysis. It consists of reperfusion catheters, separators and suction apparatus. Mechanism of action of Penumbra System is by aspiration and debulking of the thrombus thus helping to achieve re-canalization. Post procedure, all the five treated vessels $(100 \%)$ were successfully re-canalized, 


\begin{tabular}{|c|c|c|c|c|c|c|c|c|}
\hline $\begin{array}{l}\text { Age } \\
\text { (yrs) }\end{array}$ & Sex & $\begin{array}{c}\text { Duration } \\
\text { hours }\end{array}$ & Diagnosis & $\begin{array}{l}\text { TIMI score pre } \\
\text { thrombolysis }\end{array}$ & $\begin{array}{c}\text { TIMI score post } \\
\text { thrombolysis }\end{array}$ & $\begin{array}{l}\text { NIHSS } \\
\text { at onset }\end{array}$ & $\begin{array}{l}24 \\
\mathrm{hrs} \\
\end{array}$ & $\begin{array}{c}\text { mRS } \\
3 \text { months }\end{array}$ \\
\hline 38 & $\mathrm{~F}$ & 5 & BA thrombosis & 0 & 3 & 21 & 10 & 3 \\
\hline 31 & M & 7 & BA thrombosis & 0 & 3 & 42 & 42 & - \\
\hline 28 & $\mathrm{~F}$ & 2 & Left MCA(M1 segment) thrombosis & 0 & 3 & 18 & 16 & 2 \\
\hline 38 & M & 2 & Right MCA(M1 segment) thrombosis & 0 & 3 & 15 & 0 & 0 \\
\hline 59 & M & 13 & BA thrombosis & 0 & 3 & 38 & 38 & - \\
\hline
\end{tabular}

BA - Basilar artery; MCA - Middle cerebral artery; TIMI - Thrombolysis in myocardial infarction; mRS - modified Rankin score

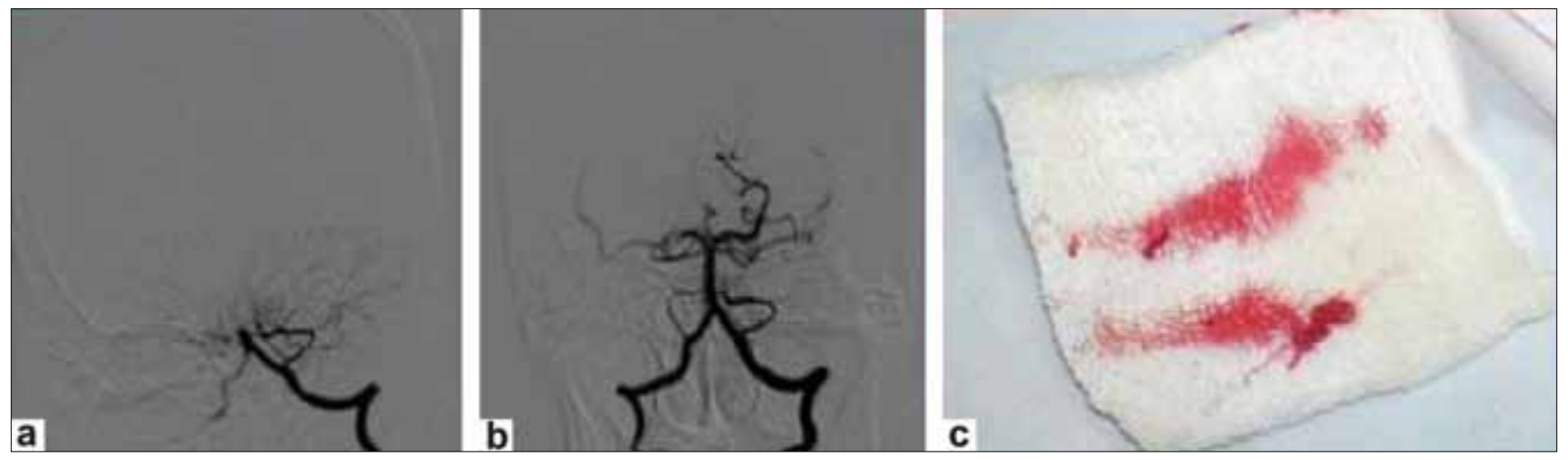

Figure 1: (a) Cerebral angio of case 1 shows complete occlusion of basilar artery, (b) Post mechanical thrombolysis shows complete recanalisation of basilar artery, (c) Clot extracted using the Penumbra system

Trials in Myocardial Infarction (TIMI) score of 3. [Figures 1 and 2] The average duration of thrombolysis was 54 min (ranging 30 to 120 minutes). The average no of reperfusion catheters used was 1.16 and the average no of separators used was 1.33. In all the patients 0.041 reperfusion catheter and separator were used. In one patient (Case 3), additional balloon angioplasty and stenting was performed as the cardio embolus was refractory to Penumbra System mechanical thrombolysis. This patient did not have improvement in NIHSS score within 24 hours of procedure, probably related to prolonged procedure time. CT done after 24 hours showed a small internal capsule infarct and infarct in temporal lobe. There were two deaths and both the deaths were not related to the procedure. One patient (Case 2) died 48 hours post procedure due to herniation secondary to cerebellar infarction and the other patient (Case 5) died after 10days due to aspiration pneumonia. No procedure related complications or intracranial hemorrhages were noted. At 24 hours follow up only one patient had a 4-point or more NIHSS improvement and 90-day follow up 2 of the 3 patients who survived had a modified Rankin score (mRS) of 2 or less.

\section{Discussion}

Management of acute ischemic stroke has always been a formidable challenge. Various treatment strategies available today lead to higher rates of recanalization. The National Institute of Neurological Disorders and Stroke study has established the benefical effect of

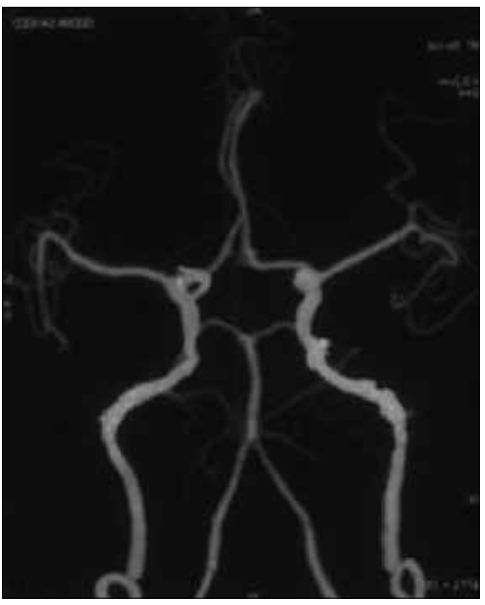

Figure 2: Follow up CT angio of case 1 shows normal cerebral angio

IV rtPA in acute ischemic stroke when given within 3 hours of onset. The benefit was $30 \%$ when compared to placebo. The risk for intracerebral hemorrhage was $6.4 \%{ }^{[4]}$ After recent ECASS III trial the window for IV thrombolysis has been extended to 4.5 hours. ${ }^{[5]}$ The window was extended to 6 hours after Prolyse in Acute Cerebral Thromboembolism $\mathrm{II}^{[6]}$ and MELT ${ }^{[7]}$ trials in which intraarterial administration of prourokinase/ urokinase has been shown to be beneficial in patients with MCA occlusion. At 90 days, $40 \%$ of r-proUK-treated subjects and $25 \%$ of control subjects had a mRs of 2 or less. Mortality for the 2 groups was similar $(25 \%$ vs. $27 \%) .{ }^{[6,7]}$ Now with the results of MERCI, MULTI MERCI and PENUMBRA study mechanical devices can be used in acute stroke up to 8 hours of onset and these devices 
can also be used in patients in whom IV thrombolysis is contraindicated. ${ }^{[5-7]}$

In this small series, of the 3 patients who survived 2 patients had mRs score of 2 or less at 90 days. Re-canalization rate was $100 \%$. None of the patients had intracranial hemorrhage. No procedure related complications were noted. In our series there were two deaths and both the deaths were not related to the procedure. One death was due to herniation within 2 days of onset of disease and the other was related to pneumonia after ten days. This study shows that mechanical thrombolysis with Penumbra System helps in early and faster thrombolysis and better recanalization in large vessel occlusion. Patients need to be selected properly and good post procedure care is mandatory. Penumbra System can be used as Primary modality in neurointerventional management of large vessel occlusive acute ischemic stroke.

In conclusion, Penumbra System is a useful device in the repertoire of endovascular management of acute stroke. It can be used either by itself or in conjunction with other devices/drugs to achieve the best results.

\section{References}

1. Smith WS, Sung G, Starkman S, Saver JL, Kidwell CS, Gobin YP, et al. Safety and efficacy of mechanical embolectomy in acute ischemic stroke: results of the MERCI trial. Stroke 2005;36:1432-8.

2. Smith WS. Safety of mechanical thrombectomy and intravenous tissue plasminogen activator in acute ischemic stroke. Results of the multi Mechanical Embolus Removal in Cerebral Ischemia (MERCI) trial, part I. AJNR Am J Neuroradiol 2006;27:1177-82.

3. Bose A, Henkes H, Alfke K, Reith W, Mayer TE, Berlis A, et al. The Penumbra System: A Mechanical Device for the Treatment of Acute Stroke due to Thromboembolism. AJNR Am J Neuroradiol 2008;29:1409 -13.

4. The National Institute of Neurological Disorders and Stroke rt-PA Stroke Study Group. Tissue plasminogen activator for acute ischemic stroke. N Engl J Med 1995;333:1581-7.

5. Hacke W, Kaste M, Bluhmki E, Brozman M, Dávalos A, Guidetti D, et al. Thrombolysis with Alteplase 3 to 4.5 Hours after Acute Ischemic Stroke. N Engl J Med 2008; 359:1317-29.

6. Furlan A, Higashida R, Wechsler L, Gent M, Rowley H, Kase C, et al. Intra-arterial prourokinase for acute ischemic stroke. The PROACT II Study: a randomized controlled trial. JAMA 1999;282:2003-11.

7. Ogawa A, Mori E, Minematsu K, Taki W, Takahashi A, Nemoto S, et al. Randomized trial of intraarterial infusion of urokinase within 6 hours of middle cerebral artery stroke. The middle cerebral artery embolism local fibrinolytic intervention trial (MELT) Japan. Stroke 2007;38:2633-9.

Accepted on 15-06-2009

Source of Support: Nil, Conflict of Interest: None declared. 